\title{
CIÊNCIANATURA
}

\section{Estudo cooperativo: uma interessante prática para o sucesso acadêmico}

Cooperative studying: an Interesting practice for academic success

João Inácio Moreira Bezerra e Rejane Pergher

Universidade Federal de Pelotas

\section{Resumo}

Os altos índices de reprovação nas disciplinas de Cálculo Diferencial e Integral, e a subsequente evasão ocasionada por eles causam preocupação em muitas universidades ao redor do mundo, tanto em países em desenvolvimento, caso do Brasil, como em países desenvolvidos, como os Estados Unidos. Então, não é surpreendente a existência de várias pesquisas que estudem os motivos desse contexto, assim como possiveis formas de ação. Este é o tema do presente artigo, ao estudar as origens desse problema, analisar as causas das dificuldades dos alunos e apresentar o Estudo Cooperativo como uma forma de mudar esta situação. $O$ artigo se baseia em dados de várias universidades que demonstraram interesse neste método. Os resultados evidenciam a efetividade desta prática, tanto no desempenho acadêmico quanto no psicológico dos estudantes, demonstrando assim a necessidade de haver um incentivo maior desta técnica, bem como um intenso estudo acerca da maneira que ela deve ser feita.

Palavras-chave: Ensino-Aprendizagem. Estudo Cooperativo. Cálculo.

\section{Abstract}

High failure rates in the Differential and Integral Calculus courses and the subsequent dropout caused by them are a reason for concern in many universities around the world, both in developing countries such as Brazil and developed ones such as the United States of America. So, it is not surprising that there is lots of interest in researching about this context, and possible ways of action. This is the focus of this article, to study about the origins of this situation, analyzing the causes of the students' difficulties and presenting Collaborative Learning as an effective way to change this situation. The article is based on data from several universities that have shown interest in this method. The results demonstrate the effectiveness of this practice, both in academic and psychological performance of the students, thus showing the need for a greater incentive of this technique, as well as an intense study of the way it should be done.

Keywords: Teaching-learning. Cooperative Study. Calculus. 


\section{Introdução}

O bom aproveitamento das disciplinas de Cálculo Diferencial e Integral é essencial para a educação de qualquer aluno dos cursos de exatas, porém muitos estudantes não o obtém, o que acaba gerando altos índices de desistência, reprovação e até evasão do curso (Hensel \& Hamrick, 2012). Essa questão é problemática não só no Brasil, mas também nas universidades de países de primeiro mundo e, em virtude disso, existem na literatura várias bibliografias examinando e propondo soluções para este problema. Essas dificuldades encontradas pelos estudantes são decorrentes de diversos motivos, sendo um deles citado por Hong et. Al. (2009), que é o número de mudanças que ocorrem na transição do ensino médio para o superior, incluindo aquelas nos modos de aprender e ensinar, tipo de matemática ensinada, entendimento conceitual, conhecimento procedural necessário para avançar no conteúdo e um aumento da importância do pensamento matemático avançado. Aqui, podemos destacar a diferença dos métodos de ensino observados durante o Ensino Médio, baseado na mecanização da Matemática para a resolução de problemas nas provas que servem como seleção para as universidades, como é o caso do Exame Nacional do Ensino Médio (ENEM) no Brasil e o Scholastic Aptitude Test (SAT) nos Estados Unidos. Além disso, no caso do ENEM, conteúdos indispensáveis para o progresso nas disciplinas matemáticas do ensino superior não são cobrados, e assim, também não são devidamente estudados.

Figura 1 - Distribuição das questões de Matemática do ENEM 1998-2014 por tipo de assunto

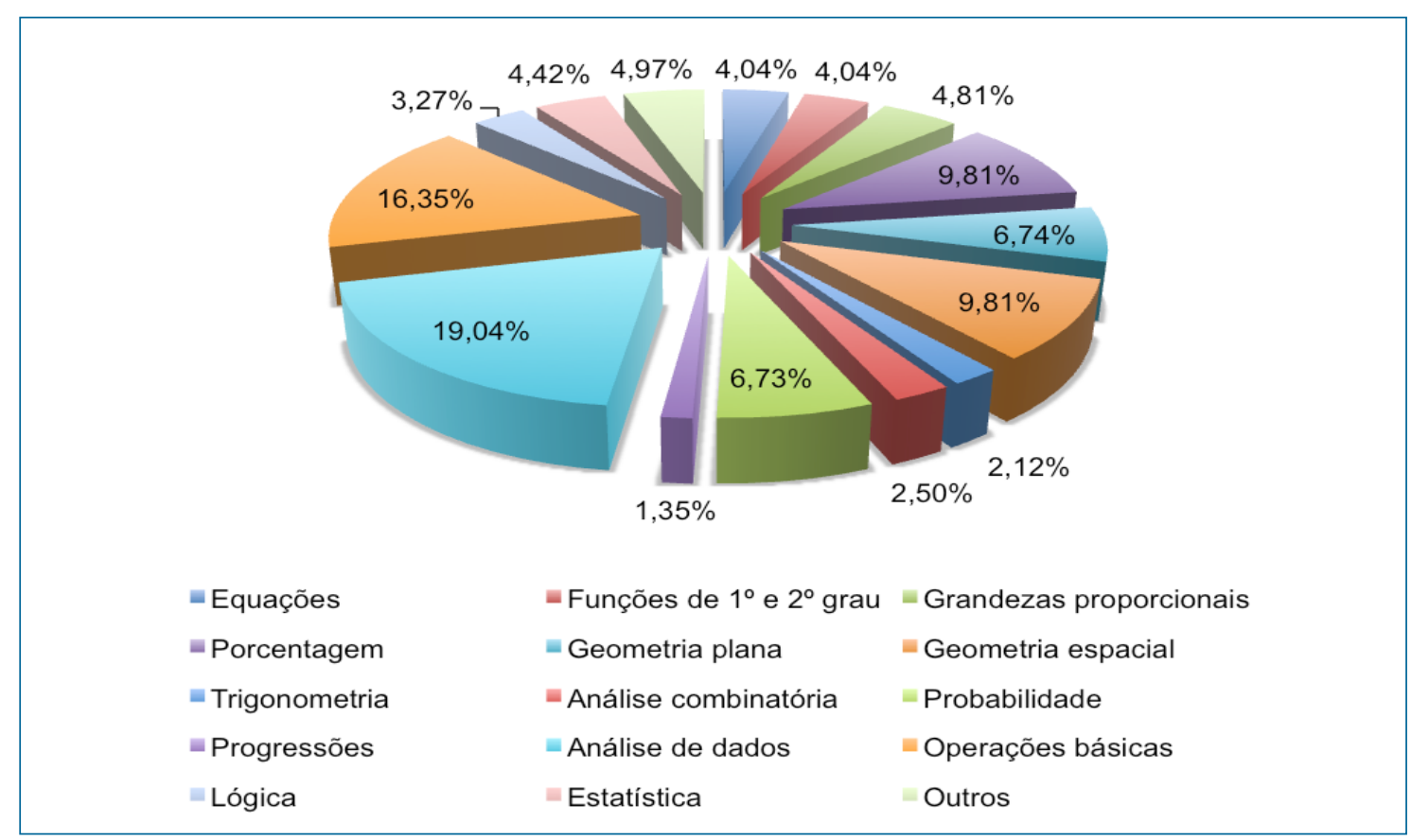

Fonte: https://blogsimplifica.files.wordpress.com/2015/07/questc3b5es-matemc3a1tica-enem.png

Já a Figura 2 refere-se a dados de um questionário proposto a alunos ingressantes na "Nome da Universidade" nos semestres de 2014/1 e 2015/1.

A Figura 2 evidencia as Funções Exponenciais e Trigonométricas como maiores dificuldades enfrentadas pelos discentes no Cálculo 1, sendo estes conteúdos abordados muito raramente na prova do ENEM, como demonstra a Figura 1 e, em consequência disso, pouco trabalhados durante o Ensino Médio. Ademais, assuntos da Matemática Básica tais como racionalização e fatoração também não são abordados, causando um grave déficit de conhecimento aos estudantes quando chegam à Universidade.

Nesse contexto, o Estudo Cooperativo é visto como uma possível solução para esta questão. Embora o mundo atual seja muito focado na competitividade, em especial nas escolas e universidades, o artigo tem o objetivo de demonstrar as vantagens da cooperação. Para isso, serão citados exemplos de práticas cooperativas no âmbito acadêmico/ profissional e sua efetividade. Na universidade, ela pode se dar de várias formas, tais como as monitorias e os grupos de estudo. 
Figura 2 - Dificuldades apontadas pelos alunos na disciplina de Cálculo 1

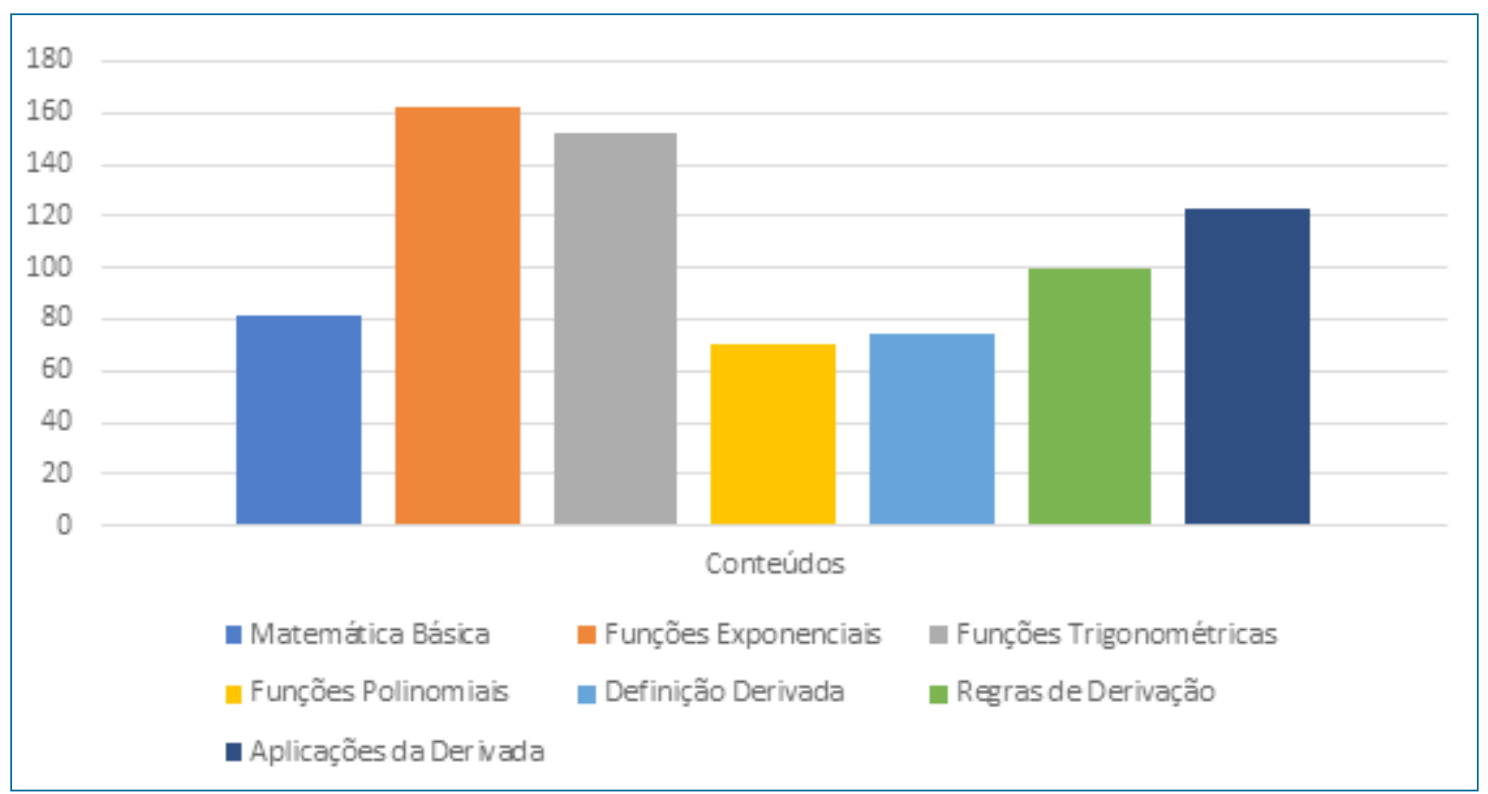

\section{Cooperação x Competição}

Esse é um debate bastante comum entre as pessoas, e existem defensores de ambos os lados, com a maioria das pesquisas acadêmicas apontando a cooperação como o melhor caminho para o sucesso. Entretanto, o sistema educacional e, em especial os pais, são grandes incentivadores da competição, sem perceber que ela em excesso causa prejuízo em negócios, menores conquistas humanas, além de causar efeitos na saúde dos estudantes, como é evidente em regiões afluentes como a do Vale do Silício, nos Estados Unidos (ROSIN, 2015). Moran (2007, p. 20) relaciona o individualismo com a falta de avanço da educação, "A educação avança menos do que o esperado porque enfrenta uma mentalidade predominante individualista, materialista, que busca as soluções isoladamente".

Buffington (20--??) destaca que cientistas que se consideram cooperativos tendem a ter mais publicações que seus colegas competitivos, empresários cooperativos têm maiores salários e, desde o ensino fundamental até o superior, estudantes cooperativos obtêm maiores notas.

Ponte (2003, apud Junior, 2004, p. 3) argumenta que a colaboração está sendo reconhecida como forma de trabalho em muitas áreas da educação e em muitos outros campos da atividade social. Para ele: "o desenvolvimento de um processo de colaboração está inevitavelmente ligado ao conteúdo e organização do trabalho".

Gillies e Boyle (2013, p5), citam os ganhos do aprendizado colaborativo, os quais são:

- Ganhos acadêmicos;

- Relações positivas no ambiente de trabalho;

- Menor necessidade de se autodisciplinar;

- Níveis de autoestima mais elevados;

- Promove a aceitação de outros;

- $\quad$ Linguagem mais inclusiva;

- Mais explicações.

Esses ganhos são de extrema importância para os alunos ingressantes em cursos de exatas, tais como as Engenharias, Matemática, Química, entre outros, levando em consideração fatores acadêmicos e psicológicos. É bastante comum um jovem chegando em um ambiente novo ter receio de não ser aceito pelos colegas, mas o estudo em grupo acaba sendo uma forma bastante positiva de integração. Além disso, com o estudo mais aprofundado da matemática, o estudante tende a ter dificuldades, as quais serão reduzidas por intermédio da linguagem mais próxima e das explicações extras de colegas. Ademais, muitos chegam à universidade sem terem enfrentado dificuldades acadêmicas, o que pode acabar tornando a autoestima sensível no início do curso. Contudo, ao manter contato com colegas que estejam passando pela mesma situação, ou também com veteranos (que podem ser monitores, ou padrinhos) que já passaram pela mesma situação e conseguiram superá-la, a autoestima tende a subir. Esse contato é destacado por Cury (2000, apud Almeida, Fatory, Souza, 2007), ao citar que depoimentos de alunos de Cálculo revelam que a interação com colegas que "falam a mesma linguagem" é fundamental para a aprendizagem.

Tendo em conta a efetividade do estudo cooperativo, iremos abordar algumas ideias para sua implementação. 


\section{Formas do Estudo Colaborativo}

Ambas as formas que serão vistas abaixo se encaixam na definição do termo inglês "peer-tutoring", definido por Topping (1996, p.322, tradução nossa) como "Estudantes de grupos sociais semelhantes que não são professores profissionais ajudando uns aos outros e ensinando a si mesmos". Como cita o autor, essa definição inclui os ganhos tanto as pessoas que são ensinadas quanto as que ensinam.

Annis (1983, apud Topping 1996, p.324) realizou um estudo em que três grupos de estudantes foram alocados de maneira randômica.

- Grupo 1: Apenas leu o material;

- Grupo 2: leu o material e pensou como iria ensiná-lo;

- Grupo 3: leu o material e ensinou o conteúdo.

No teste de 48 questões, o grupo 3 teve o melhor resultado, o grupo 2 foi o intermediário, enquanto o primeiro grupo teve o pior resultado.

\subsection{Estudo em Grupo}

Os estudantes têm a possibilidade tanto de ensinar quanto de aprender com seus colegas ao se reunirem em grupos para estudarem. Para ser bem-sucedida, essa prática deve ser bem realizada, e é necessário haver controle e liderança para evitar a procrastinação e o desvio de foco. Contudo, se bem-feita, essa prática traz muitos ganhos aos discentes, tais como:

- Reforçar as anotações: Em geral, as aulas na faculdade têm um ritmo frenético, em virtude da densidade de conteúdo, tornando difícil a tarefa de anotar todos os detalhes. Se as anotações forem compartilhadas, o que um não conseguiu anotar, o colega pode ter conseguido, e assim, ocorre a troca.

- Divisão de Talentos: Cada estudante tem áreas com mais ou menos facilidade, e elas diferem entre eles. Dessa forma, há uma troca mútua de conhecimento, beneficiando a todos.

- Gasto mais eficiente de tempo: Enquanto um estudante sozinho pode levar horas para resolver um problema, o trabalho em grupo tende a ser mais rápido, e assim é possível revisar mais a matéria.

- Sistema de Suporte: Membros de um mesmo grupo costumam ter metas em comum, como a aprovação na disciplina. Em grupo, eles irão motivar uns aos outros, e terão sempre quem procurar em caso de dificuldade, facilitando o objetivo.

- Lado Social: É melhor estudar na companhia de outras pessoas, e com isso todos estudam mais tempo.

\subsubsection{Dicas para montar o grupo}

- Número de Estudantes: De 4 a 6 membros, com mais integrantes é complicado de todos acompanharem, com menos é mais fácil de alguém se distrair e desviar o foco.

- Perfil dos Estudantes: Estudantes dedicados, que demonstram interesse pelo aprendizado, e que compartilhem os mesmos objetivos. É recomendado ter alguém no grupo que saiba mais, para ter a quem perguntar, e alguém que saiba um pouco menos, para ter a quem ensinar.

- Onde: Em um local silencioso, com bastante espaço e sem distrações.

- Quanto tempo: Não mais que duas ou três horas, o limite de tempo faz todos permanecerem focados, e um tempo maior que esse já torna o estudo cansativo.

- Quando: Se possível, um horário fixo, para estabelecer rotina.

\subsubsection{Dicas para o estudo ser bem-sucedido}

- Ter metas: Seja de terminar um capítulo, uma lista, enfim, algo que vá manter todos focados na tarefa.

- Estar preparado: Todos os membros do grupo devem ter revisado o conteúdo anteriormente, dessa forma o tempo é gasto com dúvidas pertinentes que podem ser de todos.

- Todos ensinarem: O grupo verá o conteúdo de vários pontos de vista, e todos poderão reforçar seu aprendizado.

- Manter o foco: O grupo deve possuir um líder, para manter o controle. A cada meia hora ou quarenta minutos, é efetivo uma pausa de cinco minutos para relaxar.

Contudo, como demonstra a Figura 3, a prática do Estudo em Grupo ainda não é muito comum, pelo menos na "Universidade" muito em virtude de haver poucas bibliografias em português mostrando a efetividade desta prática. 
Figura 3 - Porcentagem de alunos que estudam em grupo

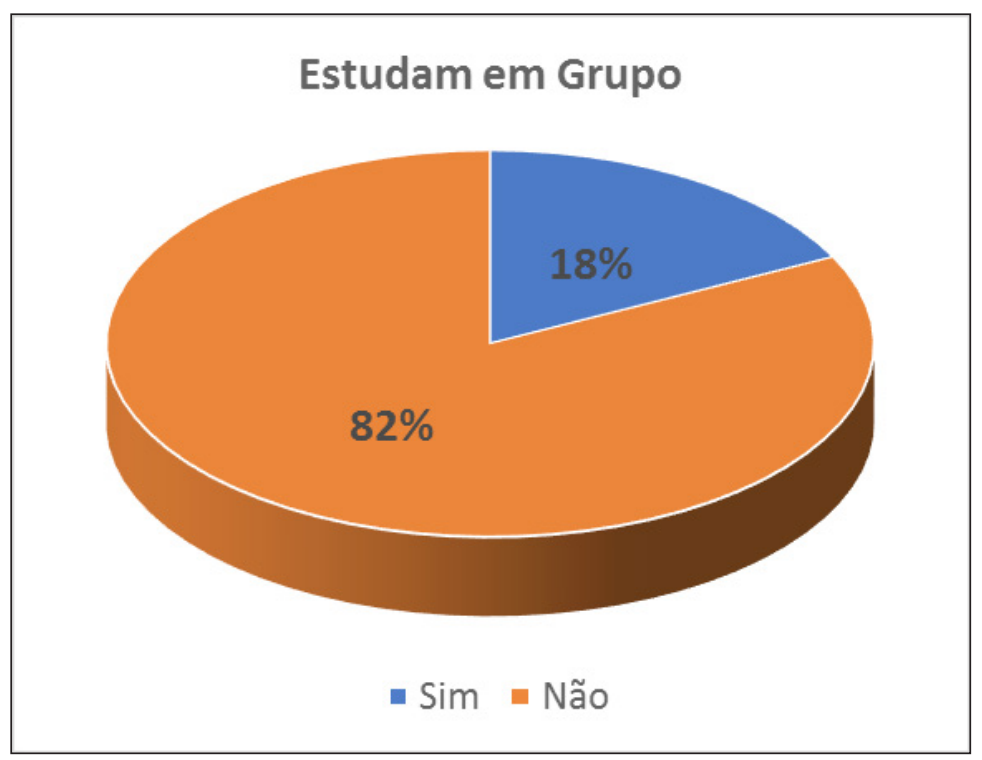

\subsection{Monitorias}

É uma forma em que basicamente, há uma ou mais pessoas que já obtiveram aprovação na disciplina que monitoram, e que estão disponíveis para sanar dúvidas dos alunos. Segundo Araújo e Moreira (2005, p2), o monitor, por ser um integrante da mesma população da categoria alvo, reúne condições favoráveis de se tornar um vetor motivacional no processo de ensino e aprendizagem. Bastante comum nas universidades, tanto de maneira online como presencial, é uma ferramenta disponível que é bastante útil aos estudantes, embora a procura muitas vezes seja baixa.

Cummings (2015, p6) cita que durante seu Ensino Médio, foi ensinada Matemática de uma maneira procedural, apenas decorando os métodos de resolver os problemas, o que não é uma maneira efetiva, tendo em vista que o conhecimento não fica memorizado, e é um problema enfrentado por muitos ingressantes. Ao entrar na universidade e se tornar uma tutora, ela ganhou o conhecimento conceitual da álgebra, geometria, trigonometria e cálculo. Assim, ela transmitiu seu conhecimento aos tutorados, que passaram a entender melhor a matéria e apresentar melhor desempenho. No ensino superior, é indispensável o entendimento conceitual do cálculo para seu bom aproveitamento, e nessa situação aparece o monitor como um auxílio no aprendizado desse conteúdo.

\subsection{1 "Nome do Projeto"}

Um exemplo dessa prática é o projeto "Nome do Projeto", na Universidade "Nome da Universidade". Formado em 2010, com o nome de "Nome antigo do Projeto", é um Programa Estratégico Institucional da universidade, com o intuito de combater a evasão dos estudantes, ao melhorar a aprendizagem nas disciplinas iniciais de matemática. Atualmente, é composto por treze bolsistas, sendo seis monitores de Cálculo 1, um monitor de Álgebra Linear e Geometria Analítica (ALGA), e os outros seis monitores se dedicam às Aulas de Reforço que são fornecidas pelo projeto durante o semestre.

O Projeto oferece várias oportunidades aos estudantes, tais como:

- Monitorias ao longo do semestre letivo;

- Aulas de Reforço durante o semestre, com módulos de Funções, Limites, Derivadas e Integrais, cada um composto por seis aulas;

- Curso Preparatório para o Cálculo (CPC), durante o recesso, para alunos ingressantes, que revisa tópicos da matemática básica cujo entendimento é indispensável para as disciplinas futuras.

Este último vem se mostrando muito efetivo para os estudantes, como demonstram as Figuras 4 e 5, contabilizadas pelos integrantes do Projeto, com dados relativos ao semestre de 2017/1. A Figura 4 refere-se à comparação do desempenho deles no Teste de Sondagem, aplicado na primeira aula do curso, e o Teste de Comparação, aplicado na última, após a revisão dos conteúdos. Já a Figura 5 destaca o bom índice de aprovação dos discentes nas disciplinas de Cálculo, após assistirem a todas as aulas do curso. 
Figura 4 - Comparação do desempenho dos Estudantes no Teste de Sondagem e no de Comparação

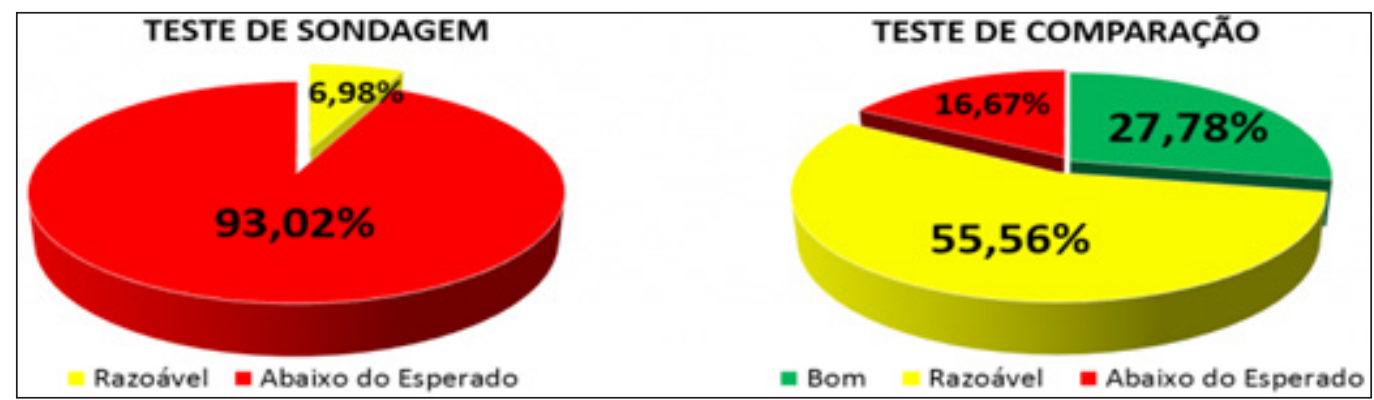

Figura 5 - Desempenho dos estudantes que assistiram a todas as aulas do Curso nas disciplinas de Cálculo subsequente

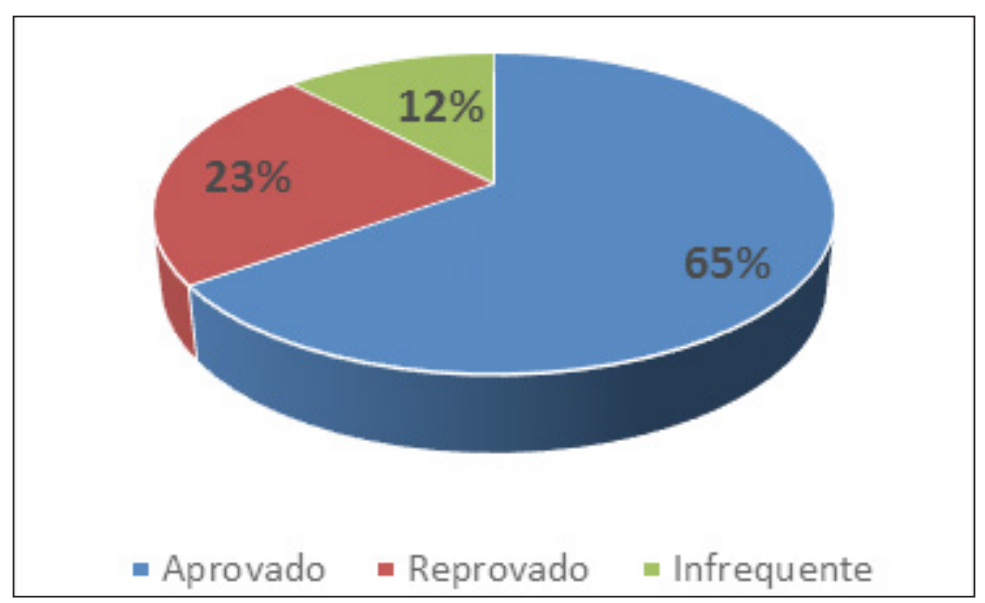

Os dados na Figura 6 também se referem ao semestre letivo de 2017/1, e demonstram a efetividade das monitorias do Projeto, tendo em vista que quanto mais frequente a procura, maior a probabilidade de o estudante obter a aprovação. Por exemplo, os estudantes que procuraram a monitoria pelo menos 16 vezes durante o semestre obtiveram $85 \%$ de aprovação.

Figura 6 - Desempenho dos estudantes que procuraram pela monitoria

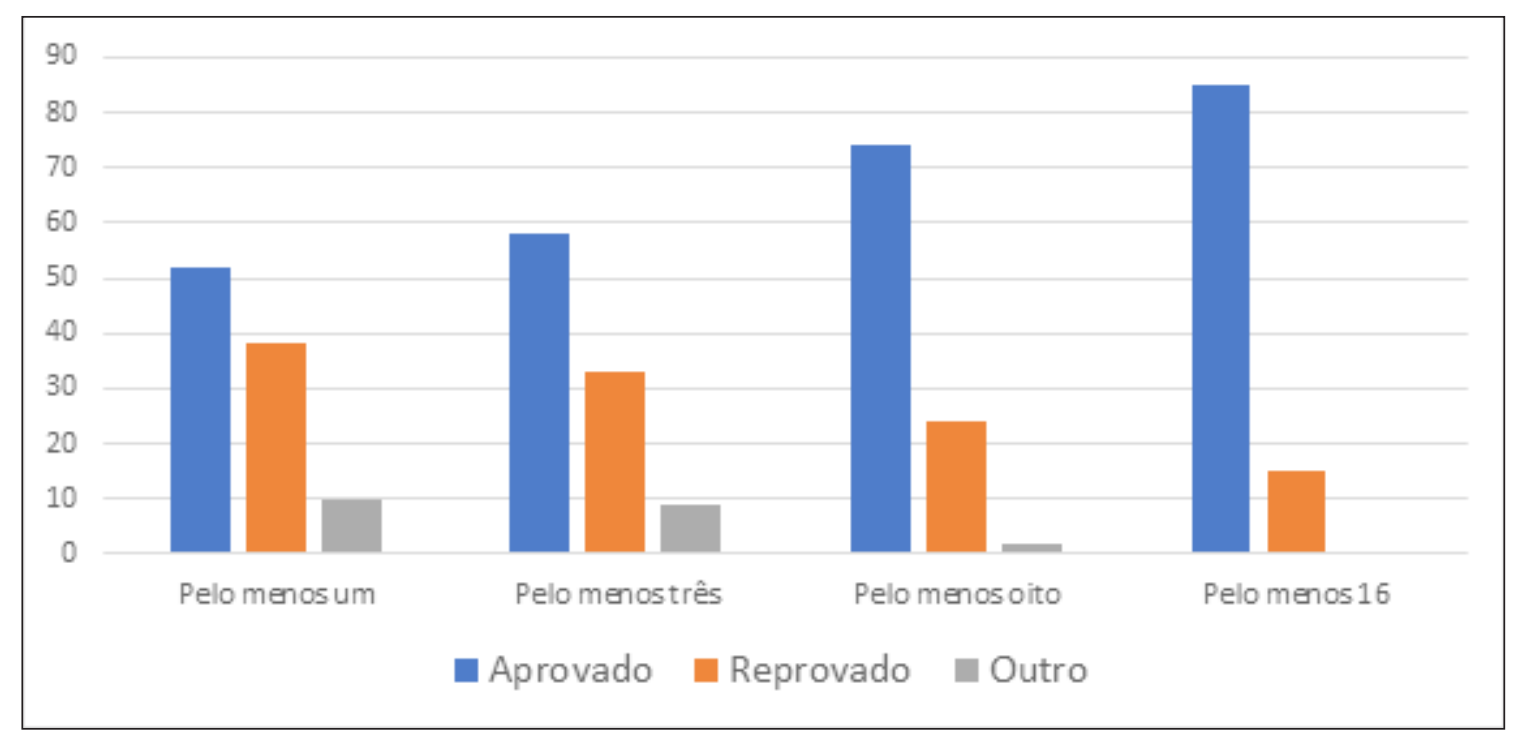


Contudo, percebe-se uma contradição no pensamento dos estudantes da instituição, tendo em vista que embora a eficácia do Projeto seja comprovada, e eles mesmos considerem o papel do monitor importante quanto a aprovação, a procura ainda é muito baixa, como é evidente na Figura 7, ainda mais considerando que muitos dos que buscam a monitoria fazem isso apenas na véspera das provas.

Figura 7 - Percentual de alunos que procuram a monitoria

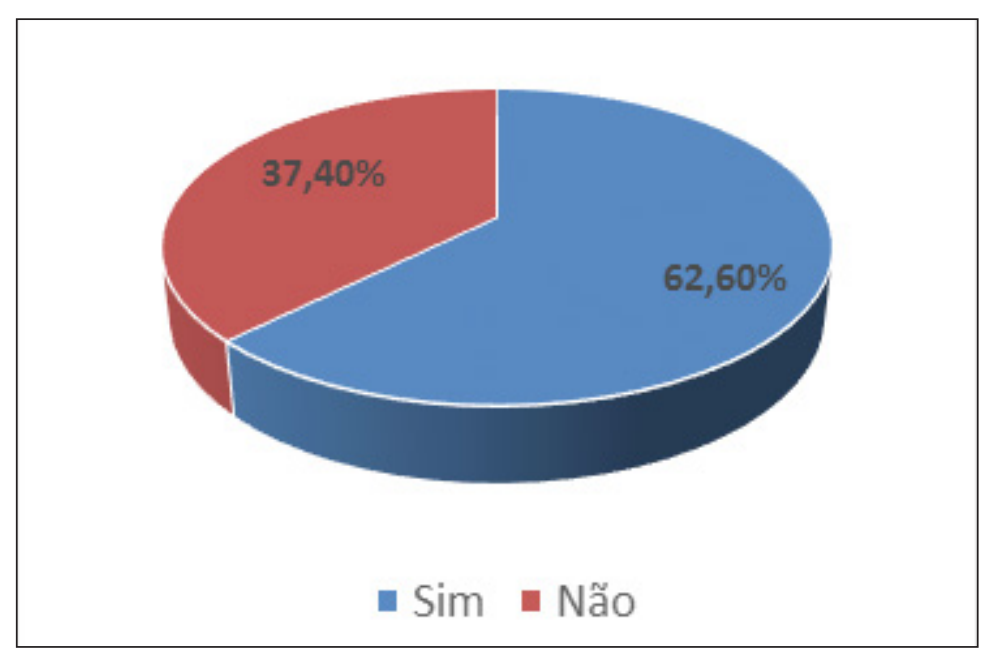

Isso demonstra a necessidade de haver mais conscientização dos estudantes acerca da importância de procurar a monitoria, e também da necessidade de fazer isso desde o começo do semestre, e não apenas perto das avaliações.

\section{Estudo Cooperativo Atualmente}

Shakerdge (2016) cita os exemplos das universidades de Nebraska-Lincoln e de San Diego State, nos Estados Unidos, que preocupadas com as altas taxas de reprovação nas disciplinas de Cálculo, e a consequente evasão, passaram a focar em um ensino mais ativo e cooperativo do Cálculo. O artigo nota que dessa forma, os estudantes demonstram maior interesse pelo conteúdo, focando nas tarefas ao invés de simplesmente se distrair em seus smart-phones. Na universidade de San Diego State, o foco é mais recente, então ainda não há resultados acerca desta mudança. Já em Nebraska-Lincoln, os índices de aprovação passaram de $62 \%$ no início de 2012 para $80 \%$ no outono de 2013 , e desde então esse valor não caiu.

Peña (2014) cita o exemplo das disciplinas introdutórias de Química no campus da Universidade da Califórnia em Davis, em que ao invés do método tradicional de ensino que ao longo do tempo vem se provando ineficaz, os estudantes são divididos em pequenos grupos para resolver os problemas. Na Universidade do Colorado, uma das líderes nessa mudança, milhares de estudantes foram testados com o método novo, obtendo notas $50 \%$ superiores a aqueles que foram ensinados pelo método tradicional. E na Universidade da Carolina do Norte, a mudança para o ensino ativo nas disciplinas introdutórias de Biologia melhorou o desempenho dos estudantes.

Barros, Remold, da Silva e Tagliati (2004, apud Damiani, 2008, p11) reportam ganhos significativos, em termos de compreensão conceitual e entusiasmo em relação à aprendizagem, obtidos por meio de discussões grupais de alunos de um curso de graduação em Física.

\section{Conclusões}

É evidente que o estudo colaborativo contribui para a redução dos índices de reprovação e de evasão nos cursos de exatas. Essa prática vem se tornando comum em universidades de países de primeiro mundo, o que evidencia a necessidade de ela ser mais divulgada no Brasil, tanto por professores, ao incentivar e orientar seus alunos a estudarem em grupos de maneira efetiva e organizada, como pelas Universidades, ao darem o suporte necessário para que os projetos de monitoria possam ser bem-sucedidos. Na "Nome da Universidade", é necessária a conscientização dos alunos acerca dos benefícios do estudo em grupo, levando em conta que ele também é benéfico, mas é bem menos utilizado pelos estudantes, como demonstram as figuras 3 e 7 . Atualmente, as evasões geram gastos públicos altos e falta de profissionais qualificados no mercado, assim empregos com boa remuneração estão disponíveis. Isso demonstra que ao se adequarem neste modelo, os estudantes estarão aumentando consideravelmente suas chances de conseguirem bons empregos. Além disso, um dos grandes objetivos do Brasil nas últimas décadas tem sido a de se tornar um país desenvolvido, o que se daria pelo aumento do Índice de Desenvolvimento Humano (IDH). Porém, embora a economia tenha avanços periódicos, é indispensável uma melhora do sistema educacional 
do país. Jespersen (2011) evidencia que nos países com maiores IDHs, a expectativa é que a população estude de 10 a 13 anos, aproximadamente. Já no Brasil, a média é de apenas 7,8 anos (Matoso, 2017), muito abaixo dessas nações, e não há dúvidas de que parte dessa média deve-se aos índices de evasão nas universidades. Assim, fica evidente que o Estudo Cooperativo, ao solucionar essa questão, irá ajudar no desenvolvimento brasileiro.

\section{Referências}

ALMEIDA, L. M. W, FATORI, L.H., SOUZA, L.G.S(2007). Ensino do Cálculo: Uma abordagem utilizando modelagem matemática. $\mathrm{P} 6$

ANNIS, L.F.(1983). 'The processes and effects of peer tutoring', Human Learning 2(1), 39-47.

ARAÚJO, R.; MOREIRA, L. F. N. Monitoria da disciplina de Cálculo. In: CONGRESSO BRASILEIRO DE ENSINO DE ENGENHARIA, 33, 2005, Campina Grande. Anais. Campina Grande: UFPB, 2005. CD-ROM.

BARROS, J. A. et al. Revista Brasileira de Ensino de Física, São Paulo, v. 26, n. 1, p. 63-69, 2004.

BOYLE, M. e GILLIES, R. (2013). Cooperative learning: A smart pedagogy for successful learning. Disponível em $<$ https://sydney.edu.au/education_social_work/professional_learning/resources/papers/slc-2013/cooperative-learning.pdf $>$ Acesso em: 16 de jun. 2017.

BUFFINGTON, P. W. Competition vs Cooperation, 20--??. Disponível em <http://www.charleswarner.us/articles/competit. htm>. Acesso em: 16 de jun. 2017.

CUMMINGS, K. (2015) How Does Tutoring to Develop Conceptual Understanding Impact Student Understanding?. In BSUZonors Program Theses and Projects. Item 96. Available at: http://vc.bridgew.edu/honors_proj/96.

CURY, H. N. Criação de ambientes de aprendizagem para o ensino de cálculo. Anais eletrônicos do I congresso Sul-Brasileiro de Informática na educação, 2000, p7.

DAMIANI, M. F. Entendendo o trabalho colaborativo em educação e entendendo seus benefícios. 2008. Educar, Curitiba, n. 31, p. 213-230, Editora UFPR.

HENSEL, R. A. e HAMRICK, T. R. (2012). Comparison of paths to calculus success. Proceedings of the 2012 ASEE Annual Conference, San Antonio, TX.

HONG, Y.Y., S. KER, S. e KLYMCHUK, S. Teachers perspectives on the transition from secondary to tertiary mathematics education. In Crossing divides: Proceedings of the 32-annual conference of the Mathematics Education Research Group of Australasia. 2009.

JESPERSEN, E. The value of education in the HDI and human development broadly. 2011. Disponível em: http://www.unesco. org/fileadmin/MULTIMEDIA/HQ/ED/ED_new/pdf/HDRO-UNDP.pdf Acesso em: 25 jun. 2017.

JÚNIOR, A.J.S., Ensino com Pesquisa na Universidade: A importância da Colaboração. 2004. VIII Encontro Nacional de Educação Matemática.

MATOSO, F. Tempo de estudo no Brasil é inferior ao de países de Mercosul e brics, aponta IDH. 2017. Disponível em: http:// g1.globo.com/mundo/noticia/tempo-de-estudo-no-brasil-e-inferior-ao-de-paises-de-mercosul-e-brics-aponta-idh.ghtml Acesso em: 25 jun. 2017.

MORAN, José (2007). A educação que desejamos: Novos desafios e como chegar lá. P13-27. 
PEÑA, R. P. College Reinvent Classes to Keep More Students in Science. 2014. Disponível em: https://www.nytimes. com/2014/12/27/us/college-science-classes-failure-rates-soar-go-back-to-drawing-board.html? r=0 Acesso em: 16 de jun. 2017

PONTE, J. P., Professores e Formadores Investigam a sua Própria Prática: O papel da colaboração. Zetetiké, Campinas, vol. 11, n. $20-2003$.

ROSIN, H. The Suicide Clusters at Palo Alto High Schools, 2015. Disponível em: $<$ https://www.theatlantic.com/magazine/ archive/2015/12/the-silicon-valley-suicides/413140/>. Acesso em: 15 de jun. 2017.

SHAKERDGE, K. High failure rates spur universities to overhaul math class. 2016. Disponível em: http://hechingerreport. org/high-failure-rates-spur-universities-overhaul-math-class/ Acesso em: 16 de jun. 2017

TOPPING, K.J. (1996). The effectiveness of peer tutoring in further and higher education: A typology and review of the literature. Higher Education, 32, 321-345.

\section{João Inácio Moreira Bezerra}

Universidade Federal de Pelotas, RS, Brasil

Email:jimbezerra@inf.ufpel.edu.br

Participação do autor: Escrita e Revisão do artigo

\section{Rejane Pergher}

Universidade Federal de Pelotas, RS, Brasil

Email: rejane.pergher@gmail.com

Participação do autor: Escrita e Revisão do artigo 